TITLE:

\title{
Over-Current Properties of MgB2Wire Cooled by Liquid Hydrogen Under Magnetic Field
}

\section{$\operatorname{AUTHOR}(S)$ :}

Shigeta, H.; Shirai, Y.; Shiotsu, M.; Tatsumoto, H.; Nonaka, S.; Kobayashi, H.; Naruo, Y.; Inatani, Y.

\section{CITATION:}

Shigeta, H. ... [et al]. Over-Current Properties of MgB2Wire Cooled by Liquid Hydrogen Under Magnetic Field. IEEE Transactions on Applied Superconductivity 2016, 26(3): 6200405.

\section{ISSUE DATE:}

2016-04

URL:

http://hdl.handle.net/2433/228374

\section{RIGHT:}

(C) 2016 IEEE. Personal use of this material is permitted. Permission from IEEE must be obtained for all other uses, in any current or future media, including reprinting/republishing this material for advertising or promotional purposes, creating new collective works, for resale or redistribution to servers or lists, or reuse of any copyrighted component of this work in other works.; この論文は出版社版でありません。引用の際には出版社版をご確認ご利用ください。; This is not the published version. Please cite only the published version. 


\title{
Over-current Properties of $\mathrm{MgB}_{2}$ Wire Cooled by Liquid Hydrogen under Magnetic Field
}

\author{
H. Shigeta, Y. Shirai, M. Shiotsu, H. Tatsumoto, S. Nonaka, H. Kobayashi, Y. Naruo, and Y. Inatani
}

\begin{abstract}
Liquid hydrogen $\left(\mathrm{LH}_{2}\right)$ has excellent properties such as large latent heat, low viscosity and so on. Because of these properties, $\mathrm{LH}_{2}$ is expected to be used as a coolant for high critical temperature superconductor (HTS), including $\mathrm{MgB}_{2}$. Over-critical-current properties of HTS are important for stable designs of HTS devices cooled by $\mathrm{LH}_{2}$, but temperature change of sheathed superconducting wire cannot be revealed only by current-voltage properties beyond critical current, since the current sharing ratio among $\mathrm{MgB}_{2}$ and sheath materials is not unkown. In this study, transient over-critical-current tests were performed on a short $\mathrm{MgB}_{2}$ sample cooled by $\mathrm{LH}_{2}$ under magnetic field, and the sample temperatures were calculated from test data. In addition, the test sample temperature based on the test was compared with that of the computer simulation result. It was found that the temperature change of the wire just after the transport current exceeds the critical current is affected by external magnetic fields.
\end{abstract}

Index Terms-Liquid hydrogen, $\mathbf{M g B}_{2}$ wire, Over-current Properties

\section{INTRODUCTION}

$\mathrm{L}$ IQUID HYDROGEN $\left(\mathrm{LH}_{2}\right)$ is expected to be used as a coolant

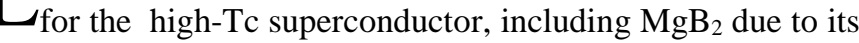
excellent properties, such as large latent heat, low viscosity coefficient and so on. It is necessary for a stability design of the high Tc superconductor cooled by $\mathrm{LH}_{2}$ to make the overcurrent properties clear.

In case of a high-Tc superconductor, the critical current is not the absolute limit of cooling stability. As the specific heat of the materials in $\mathrm{LH}_{2}$ or liquid nitrogen $\left(\mathrm{LN}_{2}\right)$ is larger than that in liquid helium (LHe), "thermal runaway" phenomenon is important for the cooling stability. When the conductor is cooled by $\mathrm{LH}_{2}$ or $\mathrm{LN}_{2}$, cooling limit due to critical heat flux of nucleate boiling may correspond to several ten times of the critical current. It is necessary for stable cooling to know the temperature of the wire with over-current.

The current distribution ratio of the sheath and the

This work is supported partially by JST-ALCA. The authors thank technical staffs of JAXA for their technical assistance.

H. Shigeta, Y. Shirai, M. Shiotsu are with Dept. of Energy Science \& Technology, Kyoto University, Sakyo-ku, Kyoto 606-8501, Japan

(e-mail: shigeta@pe.energy.kyoto-u.ac.jp; shirai.yasuyuki.7v@kyoto-u.ac.jp; shiotsu@pe.energy.kyoto-u.ac.jp )

H. Tatsumoto is with J-PARC Center, Japan Atomic Energy Agency, Tokai, Ibaraki, 319-1195, Japan (e-mail: tatumoto@post.j-parc.jp )

S. Nonaka, H. Kobayashi, Y. Naruo, Y. Inatani are with Institute of Space and Astronautical Science, JAXA, Kanagawa, 229-8510, Japan (e-mail: nonaka.satoshi@jaxa.jp; kobayashi.hiroaki@jaxa.jp; naruo@isas.jaxa.jp; inatani@isas.jaxa.jp) superconductor is needed to calculate the temperature of the wire at the over-current condition. However, the ratio depends on both the temperature of the wire, that is the resistance of the components, and the transport current. Therefore the wire temperature cannot be calculated only from a $V-I$ characteristic under steady state conditon.

Using the results of over-current test in some transient conditions with several time constants and applying the transient heat method [1], several $V$-I characteristics for a test wire in different combinations of temperature and transport current are obtained. The distribution ratio and the average temperature of the wire can be calculated. The resistivity of the $\mathrm{MgB}_{2}$ superconductor with over-current can be expressed as the function of the temperature and the transport current.

Hikawa [2] has reported the over-current properties of the $\mathrm{MgB}_{2}$ wire submerged in $\mathrm{LH}_{2}$. Over-current tests were carried out at the bulk temperatures of $21 \mathrm{~K}, 24 \mathrm{~K}, 27 \mathrm{~K}$ and $29 \mathrm{~K}$ under the pressure of $1100 \mathrm{kPa}$. The test sample was heated by exponential heat inputs $Q=Q_{0} \mathrm{e}^{\mathrm{t} / \tau}$ with wide range of the periods $\tau$ up to $10 \mathrm{~s}$. The investigation was stopped at the first appearance of electrical resistivity of $\mathrm{MgB}_{2}$.

In this study, transient over-critical-current tests were performed on a short $\mathrm{MgB}_{2}$ sample cooled by $\mathrm{LH}_{2}$ under magnetic field. The results are analyzed by using the transient heat method, and are extended to the temperature change of the wire. In addition, numerical simulations were performed by modeling the $\mathrm{MgB}_{2}$ superconducting wire and the results of the simulations were compared with that of the transient heat method.

\section{EXPERIMENTAL APPARATUS AND PROCEDURE}

\section{A. Experimental Set-up}

Fig. 1 shows the schematic diagram of the $\mathrm{LH}_{2}$ test cryostat. The cryostat has $309.5 \mathrm{~mm}$ inner diameter and has $2122 \mathrm{~mm}$ height.

Magnetic field can be set to $0-7.0 \mathrm{~T}$ by use of the $\mathrm{Nb}-\mathrm{Ti}$ superconducting magnet cooled by LHe. Pressure in the $\mathrm{LH}_{2}$ test cryostat can be set to 0.1-2.0 MPa by use of the feed hydrogen gas line. The bulk temperature can be changed by use of the sheathed heater equipped at the bottom of the cryostat. Electric current can be applied to the test sample up to 600 A by use of DC power sources.

The detail of this experimental set-up for investigating electrical properties of superconductors cooled by $\mathrm{LH}_{2}$ under magnetic field was described by Shirai [3]. 


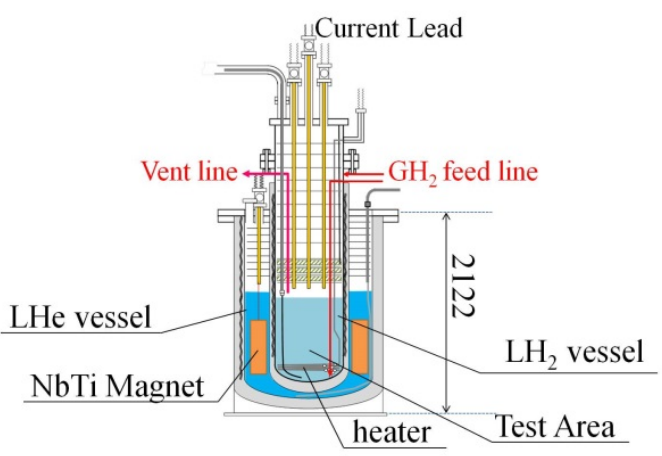

Fig. 1. The schematic diagram of the $\mathrm{LH}_{2}$ test cryostat.

\section{B. Test Sample}

The photo of the test sample is shown in Fig.2, and the schematic diagram is shown in Fig.3.

The test $\mathrm{MgB}_{2}$ wire is provided by Hyper Tech, Co. The test $\mathrm{MgB}_{2}$ wire is $160 \mathrm{~mm}$ in length, $0.83 \mathrm{~mm}$ in diameter. The width between current leads is $105.5 \mathrm{~mm}$, and that between voltage taps is $47.65 \mathrm{~mm}$. The cross section ratio of $\mathrm{MgB}_{2}$, Nb-barrier, and Cu-sheath is $0.200,0.382$, and 0.418, respectively. The copper plates are soldered at both end of the test wire, and the copper current leads are soldered on the copper plates. Additionally, the BSCCO power leads are soldered at both end of the test wire in order to avoid the joule heat generation from the power leads. The platinum voltage taps are soldered on the sample surface. The test sample is set in the cryostat with its length direction horizontal. A plate made of fiber reinforced plastic (FRP) is set close to the test wire in order to avoid deformation caused by Lorentz force.

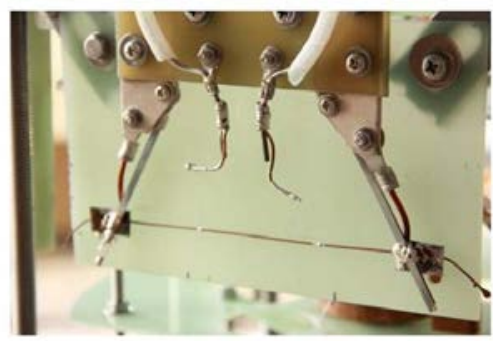

Fig. 2. The photo of the test sample

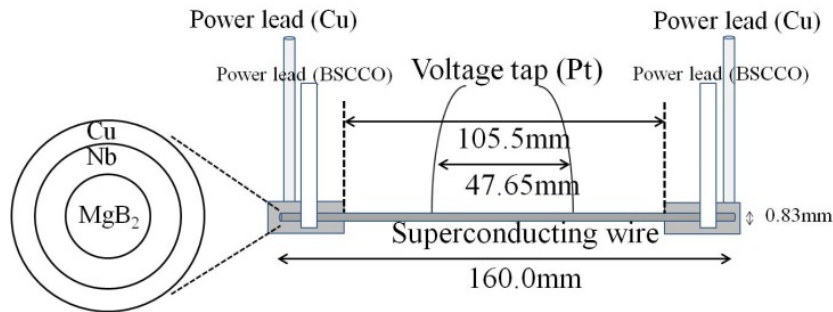

Fig. 3. The schematic diagram of the test sample

\section{Experimental Process}

The test sample was heated by applying the electric current $I$ which exceeds the critical current $I_{\mathrm{C}}$. The theoretical expression of the heat transfer characteristics of a thin round wire in non-boiling regime was given by Shiotsu[1]. The heat flux and the temperature rise of the heated wire surface changes in accordance with the expression. The surface temperature was evaluated by fitting the experimental nonboiling heat transfer curves with several rising speeds of the heat input to to the theoretical expressions. The heat input was controlled as $Q=Q_{0} \mathrm{e}^{t / \tau}$ with some kind of periods $\tau$ which is considered as transient heat input.

In this experiment, the initial current $I$ was about $7.5 \mathrm{~A}$ and the current increased exponentially before it reached $I_{\mathrm{C}}$. After $I$ reached $I_{\mathrm{C}}$, it was controlled so as to give exponential heat inputs $Q=Q_{0} \mathrm{e}^{t / \tau}$ with the periods $\tau$ ranging from $10 \mathrm{~s}$ to $50 \mathrm{~ms}$. The heat input tests were carried out at the bulk temperatures of $21 \mathrm{~K}, 24 \mathrm{~K}, 27 \mathrm{~K}$ and $29 \mathrm{~K}$ under the pressure of $1100 \mathrm{kPa}$. The magnetic fields were set to $0 \mathrm{~T}, 0.2 \mathrm{~T}, 0.4 \mathrm{~T}$, and $0.8 \mathrm{~T}$.

\section{The Transient Heat Method}

The transient heat method is the way to calculate the resistivity of $\mathrm{MgB}_{2}$ with over-current as the function of the average temperature of the wire and the transport current like the following Eq. (1).

$$
R(T)=R_{\mathrm{N}}(T)\left[1.0-1.0 /\left\{(1.0-a)+a\left(I / I_{\mathrm{C}}\right)^{m}\right\}^{0.1}\right]
$$

In this equation, $a$ and $m$ are fixed numbers, $I$ is the total current through the sample, $R$ is the resistance of the sample, and $R_{\mathrm{N}}$ is combined resistance of the substrate. The combined resistance $R_{N}(T)$ is previously obtained from literature data of resistivity versus temperature curves for $\mathrm{Nb}$ and $\mathrm{Cu}$ as a parallel resistance of the tubes. $I_{\mathrm{C}}$ is the critical current as the function of the average temperature of the wire.

If the fixed numbers $a$ and $m$ are assumed, $T$ can be calculated. In this method, the experimental heat transfer curves were fitted to the theoretical expression of non-boiling heat transfer coefficients, and the $a$ and $m$ were determined for the experimental data with each magnetic field.

Fig.4 shows one of experimental results at the bulk temperature of $21 \mathrm{~K}$ under the pressure of $1100 \mathrm{kPa}$. The transport current rises continuously, and the resistance of the wire appeared when the transport current exceeded the critical current. Fig. 5 shows the relation between the critical current and the temperature of the $\mathrm{MgB}_{2}$ superconducting wire for each magnetic field obtained from the V-I characteristics of the wire.

Using these experimental results and Eq.(1), the heat transfer coefficient curves fitted to the theoretical expression are obtained and the values $a$ and $m$ were determined for each magnetic field. Fig.6 shows the heat transfer curves in the condition of $0 \mathrm{~T}$ of magnetic field. The heat transfer curves for each period are plotted, and the red broken lines are the theoretical expressions.

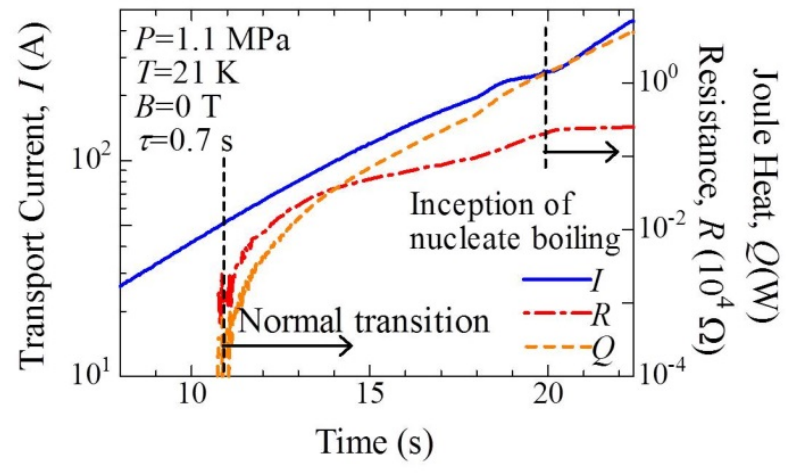

Fig. 4. Experimental result with heat input test 


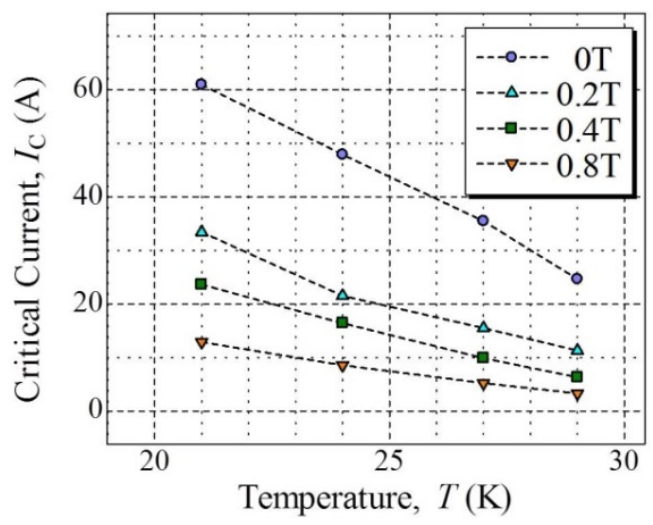

Fig. 5. Relation between the critical current and the temperature of the wire for each magnetic field

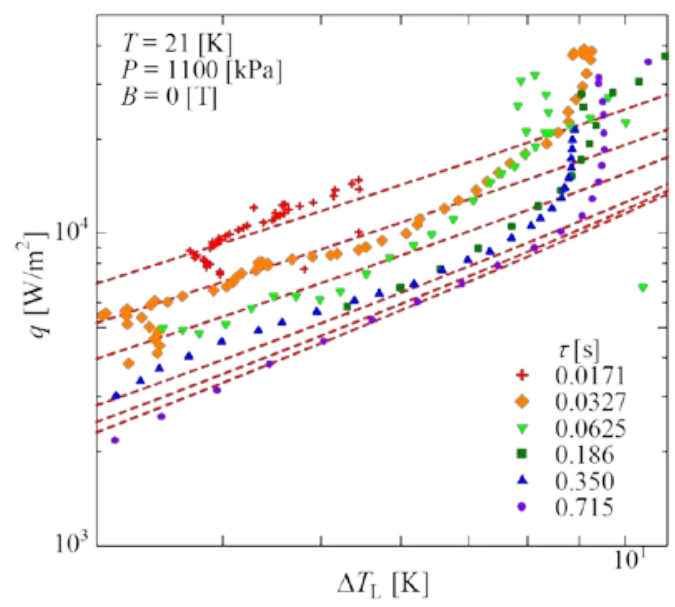

Fig. 6. Heat transfer curves fitted to the theoretical expression in the condition of $0 \mathrm{~T}$.

The fixed numbers $a$ and $m$ of Eq.(1) were determined as 0.38 and 2.60 for $0 \mathrm{~T}$ of magnetic field. Under magnetic field, $a$ and $m$ were determined as 0.23 and 2.50 for $0.2 \mathrm{~T}, 0.23$ and 2.30 for $0.4 \mathrm{~T}, 0.30$ and 2.35 for $0.8 \mathrm{~T}$. Finally, the relations between the average temperature of the wire and the transport current were obtained from Eq.(1).

\section{RESULTS}

\section{A. Temperature Change of the Wire}

Hikawa[2] mentioned only about the results of the resistivity of the $\mathrm{MgB}_{2}$ superconductor, and in this study the changes of the average temperature of the wire were observed closely.

Fig.7 shows the temperature change for various periods $\tau$ at the bulk temperature of $21 \mathrm{~K}$ under the pressure of $1100 \mathrm{kPa}$. $T$ is the average temperature of the $\mathrm{MgB}_{2}$ wire, and $I$ is the transport current. Both $T$ and $I$ are the transient value. In this graph, $T$ starts to rise at the critical current and increases to saturation temperature.

In the cases of $0.71 \mathrm{~s}, 0.35 \mathrm{~s}$, and $0.18 \mathrm{~s}$, the smaller the period is, the larger the transport current for the same temperature is. For example, the transport currents at $27 \mathrm{~K}$ are about $230 \mathrm{~A}, 250 \mathrm{~A}$, and 295A. The faster the heat input rises, the larger the transport current should rise before the temperature reaches $27 \mathrm{~K}$.

However, in the cases of $0.062 \mathrm{~s}$ and $0.035 \mathrm{~s}$, the smaller the period is, the faster the temperature rises just after the transport current exceeds the critical current. If the speed of heat input increasing is larger than that of thermal conduction in the wire, the temperature of the center of the wire may be larger than that of the surface. In such case, the amount of cooling by $\mathrm{LH}_{2}$ may be less than the case that the wire does not have a temperature gradient. Therefore, if the period is too small, the temperature of the wire rises rapidly just after the transport current exceeds the critical current.

In the transient heat method, the temperature gradient is not concerned so it seems that the temperature with small periods was not calculated correctly enough.

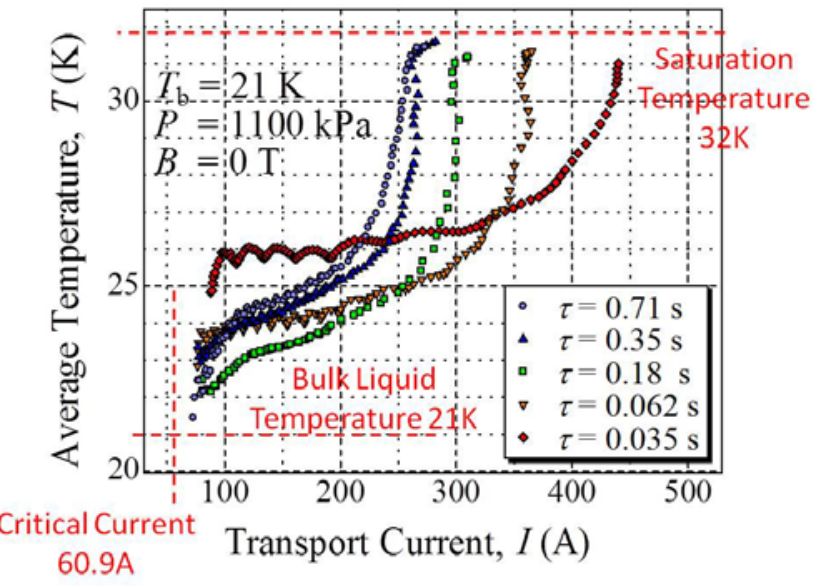

Fig. 7. Temperature with transport current for various periods $\tau$ at the bulk temperature of $21 \mathrm{~K}$ under the pressure of $1100 \mathrm{kPa}$.

\section{B. Temperature Change at the other bulk temperature}

Fig.8 shows the temperature change for various periods $\tau$ at the bulk temperature of $24 \mathrm{~K}$.

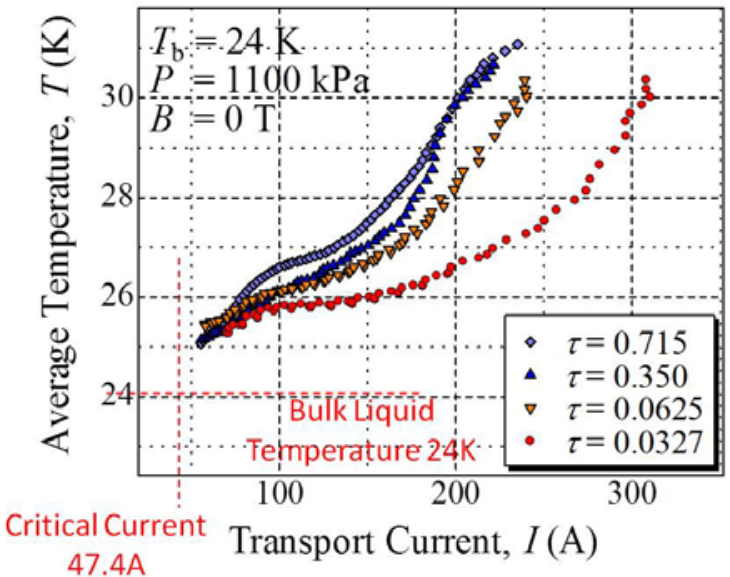

Fig. 8. Temperature with transport current for various periods $\tau$ at the bulk temperature of $24 \mathrm{~K}$ under the pressure of $1100 \mathrm{kPa}$

For all period conditions, the smaller the period is, the larger the transport current for the same temperature is. This tendency is noticed in the results of the bulk temperature of $27 \mathrm{~K}$ and $29 \mathrm{~K}$. If the bulk temperature is higher, specific heat 
and thermal conductivity of the wire is higher. It seemed that the temperature gradient did not occur when the bulk temperature was higher than $21 \mathrm{~K}$.

\section{Temperature Change under Magnetic Field}

Fig.9 shows the temperature change for various periods $\tau$ under magnetic field of $0.8 \mathrm{~T}$ at the bulk temperature of $21 \mathrm{~K}$ under the pressure of $1100 \mathrm{kPa}$.

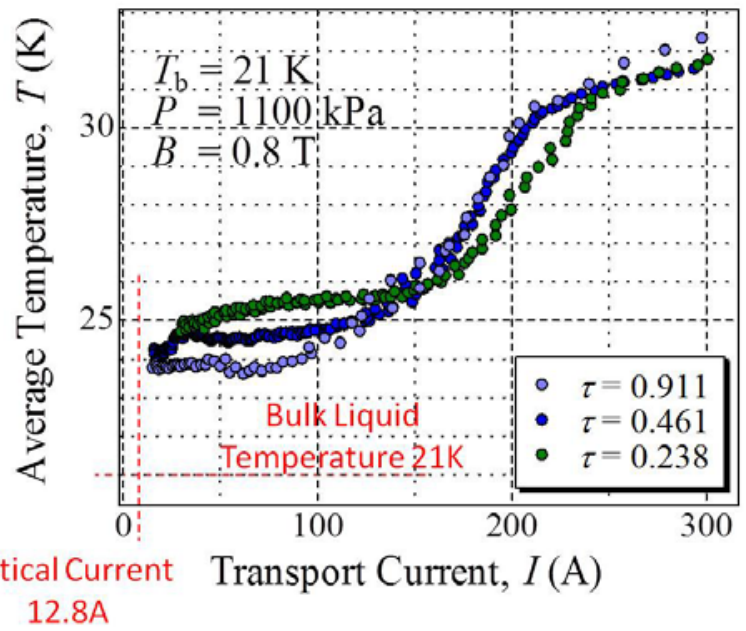

Fig. 9. Temperature with transport current for various periods $\tau$ at the bulk temperature of $24 \mathrm{~K}$ under the pressure of $1100 \mathrm{kPa}$ under magnetic field of $0.8 \mathrm{~T}$

In the case of $0.911 \mathrm{~s}, 0.461 \mathrm{~s}$ and $0.238 \mathrm{~s}$, the smaller the period is, the faster the temperature rises just after the transport current exceeds the critical current. This tendency can be seen in the case of Fig.7 with small period too. However, under magnetic field of $0.8 \mathrm{~T}$, the period at which this tendency occurs is larger than $0 \mathrm{~T}$.

When external magnetic field is applied to $\mathrm{MgB}_{2}$, the n-value of $\mathrm{MgB}_{2}$ goes down and flux flow resistivity just after the transport current exceeds the critical current increase more quickly. Therefore, under external magnetic field, the wire seems to have temperature gradient even if the order of the period is $0.1 \mathrm{~s}$.

\section{Discussions}

In the transient heat method, the tap voltage $V$ is described as following Eq.(2).

$$
V=r(T) I_{\mathrm{S}}=R_{\mathrm{N}}(T)\left(I-I_{\mathrm{S}}\right)
$$

In this equation, $r$ is the resistance of the superconductor, $I_{S}$ is the current which flows through $\mathrm{MgB}_{2}, I_{\mathrm{C}}$ is the critical current, $R_{\mathrm{N}}$ is the resistance of the sheath (Cu and $\left.\mathrm{Nb}\right)$, and $I$ is the transport current. The heat generation at $\mathrm{MgB}_{2}$ is calculated by $r I_{\mathrm{s}}{ }^{2}$ in the transient heat method, using $r(T)$ obtained as described before.

If the resistance $r(T)$ is unknown, the current sharing ratio of $\mathrm{MgB}_{2}$ and the sheath $I_{\mathrm{S}} /\left(I-I_{\mathrm{S}}\right)$ cannot be fixed. In order to verify the transient current method, a numerical simulation was carried out with the simple assumption $I_{\mathrm{S}}=I_{\mathrm{C}}(T)$ where
$r(T)$ is unknown, and the heat generation at $\mathrm{MgB}_{2}$ is calculated by $\operatorname{VIc}(T)=R_{\mathrm{N}}(T)(I-I \mathrm{c}(T)) \operatorname{Ic}(T)$.

The influence of $I^{\prime}$ which is described as $I^{\prime}=I_{\mathrm{S}}-I_{\mathrm{C}}$ was discussed by comparing simulation results and experimental results analyzed by the transient current method.

Fig.10 shows one-dimensional model in the simulation. The simulation model of the $\mathrm{MgB}_{2}$ wire is shown in Fig.3, and thermal conduction in the radial direction of the wire was analyzed by solving the equation of heat conduction with implicit finite difference method. The radial direction of the wire was divided into 20 meshes and the transport current was set so as to give exponential heat input. To calculate the heat flux of the wire into $\mathrm{LH}_{2}$, the heat transfer curve of PtCo wire immersed in $\mathrm{LH}_{2}$ which was reported by Horie [4] was used.

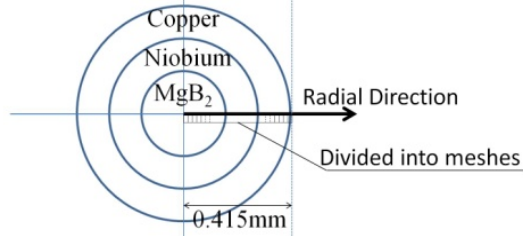

Fig. 10. One-dimensional model of the $\mathrm{MgB}_{2}$ wire

Fig.11 shows the results of the temperature change with transport current for various periods $\tau$ at the bulk temperature of $21 \mathrm{~K}$ under the pressure of $1100 \mathrm{kPa}$. The simulation data are plotted, and the broken lines are the experimental results.

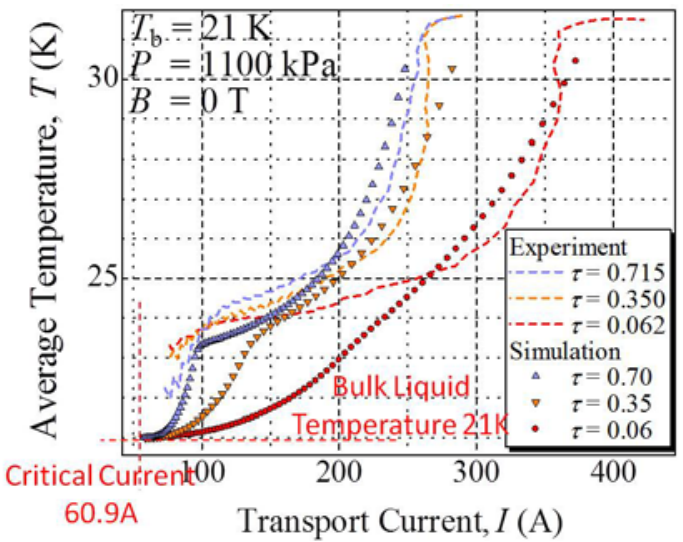

Fig. 11. Temperature with transport current calculated in the simulation

The temperature of the simulation just after the transport current exceeds the critical current are smaller than those of the experiment. This tendency is remarkable when the period $\tau$ is small. When the transport current is small, $R_{\mathrm{N}}$ may be much larger than $r$. In this region, the heat generation is mostly caused by $I_{\mathrm{S}}$ and therefore $I$ ' strongly influences on the temperature. The temperature in the simulation is calculated lower. When the period $\tau$ is small, the transport current $I$ increases rapidly, and $I$ at the same temperature $T$ becomes large compared with that with large $\tau$. Therefore, the difference between the simulation and the experimental result analyzed by the transient heat method is large where the period $\tau$ is small.

On the other hand, in the area of high transport current, the temperature of the simulation is almost same as that of the experiment. This is because $r$ is much larger than $R_{\mathrm{N}}$ in this area, and $I^{\prime}$ is quite small. 
In short, the influence of $I^{\prime}$ cannot be neglected just after the transport current exceeds the critical current. The transient heat method can be used for evaluation of the $\mathrm{MgB}_{2}$ resistance $r(T)$ and temperature of the wire during over-current operation.

\section{CONCLUSION}

In this study, the critical current of the $\mathrm{MgB}_{2}$ short wire immersed in $\mathrm{LH}_{2}(21 \sim 29 \mathrm{~K})$ was measured under magnetic fields $(0 \sim 1 \mathrm{~T})$. The over-current test was carried out for various heat input speed, and the temperature change of the $\mathrm{MgB}_{2}$ wire was evaluated by using the transient heat method.

In the case of fast heat input, the temperature increases fast just after the transport current exceeded the critical current. This shows the wire may have the temperature gradient between the center and the surface. This tendency was remarkable under magnetic field.

In addition, numerical simulations were performed, and the result shows the temperature change just after the transport current exceeds the critical current is particularly influenced by the heat generation at the superconductor $\left(\mathrm{MgB}_{2}\right.$ part). The transient heat method can evaluate the temperature which contains this influence.

The transient current method can be used for evaluation of the $\mathrm{MgB}_{2}$ resistance $r(T)$ and temperature of the wire during over-current operation, and these procedures can be used to evaluate stability of HTS devices.

\section{REFERENCES}

[1]. M. Shiotsu, K. Hata, A. Sakurai, C. Suzawa, S. Isojima, K. Sato, and T. Fukui, Electrical resistivity of a high- $\mathrm{T}_{\mathrm{C}}$ superconductor for electric current higher than $\mathrm{I}_{\mathrm{C}}$, Advances in Cryogenic Engineering (Materials), Plenum Press, New York ,44, pp. 623-629(1998)

[2]. K. Hikawa, Y. Shirai, T. Takegami, M. Shiotsu, H. Tatsumoto, K. Hata, H. Kobayashi, Y. Naruo, Y. Inatani, N. Narita: "Over-current characteristics of $\mathrm{MgB}_{2}$ wire cooled by liquid hydrogen", ICEC 24ICMC 2012, Fukuoka, Japan, pp.203-206(2012), ISBN 978-4-9906959$0-3$

[3]. Y. Shirai, H. Kobayashi, T. Takegami, K. Hikawa M. Shiotsu, H. Tatsumoto, Y. Naruo, H. Kobayashi, Y. Inatani, K. Kinoshita, Over current properties of HTC superconducting wire cooled by liquid hydrogen, European Conference on Applied Superconductivity , Hague, Netherlands, Physics Procedia, 36, pp. 1384-1389(2011), http://dx.doi.org/10.1016/j.phpro.2012.06.309

[4]. Y. Horie, Y. Shirai, M. Shiotsu, K. Yoneda, T. Matsuzawa, H. Tatsumoto, Y. Naruo, H. Kobayashi, H. Inatani: "Film boiling heat transfer properties of liquid hydrogen in natural convection", ICEC25 \& ICMC 2014, Thu-Mo-P3.3-6, University of Twente, Netherland, Physics Procedia, 67, pp. 643-648(2015) 